\title{
OPEM
}

www.opem.org

Oriental Pharmacy and Experimental Medicine 2009 9(2), 157-163

DOI 10.3742/OPEM.2009.9.2.157

\section{Anti-inflammatory activity of methanol extract isolated from stem bark of Albizia julibrissin}

\author{
Ho-Jeong $\mathrm{Na}^{1}$, Dong-Seok $\mathrm{Cha}^{2}$ and Hoon Jeon ${ }^{2,3, *}$ \\ ${ }^{I}$ Division of Allergy and Clinical Immunology, Johns Hopkins University School of Medicine, Johns Hopkins \\ Asthma Center, Baltimore, Maryland, USA; ' Department of Oriental Pharmacy, College of Pharmacy, Woosuk University, \\ Chonbuk, Republic of Korea Department of Medicine; ${ }^{3}$ Center for Healthcare Technology Development, Republic \\ of Korea
}

Received for publication April 20, 2009; accepted June 10, 2009

\begin{abstract}
SUMMARY
Albizia julibrissin (AJ) has been used widely as a traditional medicine. In macrophages nitric oxide (NO) is released as an inflammatory mediator and has been proposed to be an important modulator of many pathophysiological conditions including inflammation and carcinogenesis. In this study we have examined the NO inhibition effect of $85 \%$ methanol extracts of AJ in mouse macrophage. Lipopolysaccharide (LPS) has been reported to induce production of NO. Extracts of AJ $(1,10,100 \mu \mathrm{g} / \mathrm{ml})$ suppressed nitric oxide production in LPS-stimulated $(100 \mu \mathrm{g} / \mathrm{ml})$ mouse (C57BL/6) macrophages and analyzed by ELISA. In addition, it also attenuated the expression of inflammatory products like Interleukin-6 (IL-6), cyclooxygenase-2 (COX-2), and inducible NOS (iNOS) as assessed by immunoblotting with specific antibodies. These results suggest that $85 \%$ methanol extracts of AJ would be useful in inflammatory diseases.
\end{abstract}

Key words: Albizia julibrissin; Nitric oxide; IL-6; Cyclooxygenase-2

\section{INTRODUCTION}

The stem bark of Albizia julibrissin DURAZZ. (Leguminosae) is recorded in the Chinese Pharmacopoeia as an anti-inflammatory agent, and specified to treat injuries from falls and remove carbuncles (The Pharmacopoeia Committee of People's Republic of China, 1995). It is well known as sedative drug for treating skin ulcers, wounds or swelling and pain of the lungs (Zhang, 2005).

Macrophage activation is known to play an important role in the inflammatory process

\footnotetext{
*Correspondence: Hoon Jeon, Department of Oriental Pharmacy, College of Pharmacy, Woosuk University, Chonbuk, Republic of Korea. Tel: +82632901577; Fax: +82632901576; E-mail: hna4@jhmi.edu
}

(Medzhitov and Janeway, 1997a; Beutler 2000) and produce potent pro-inflammatory cytokines such as tumor necrosis factor (TNF)- $\alpha$ and interleukin (IL)-6 which induce inflammation and recruit other immune cells, e.g., neutrophils and T lymphocytes (Medzhitov and Janeway, 1997b). Although these pro-inflammatory cytokines are beneficial to the host defense, they can also trigger pathological conditions when expressed in excess. 4) For example, massive stimulation of macrophages after a severe Gram-negative bacterial infection leads to excessive production of pro-inflammatory cytokines and the development of fatal septic shock syndrome, and multiple organ failure (Parrillo, 1993; Beutler, 1995) and activate pro-inflammatory genes. In addition, higher levels of pro-inflammatory cytokines are 
also implicated in a variety of chronic inflammatory diseases including rheumatoid arthritis, psoriasis, and Crohn's disease (Beutler, 1995).

Macrophages are a first line of defence against microbial invaders and malignancies by nature of their phagocytic, cytotoxic and intracellular killing capacities (Adams and Hamilton, 1984). Macrophage activation by lipopolysaccharide (LPS), the major component of gram-negative bacteria cell wall, results in the release of several inflammatory mediators such as nitric oxide (NO). The physiologic or normal production of $\mathrm{NO}$ from phagocytes is beneficial for the host defense against microorganism, parasites, and tumor cells (Thiemermann and Vane, 1990). However, overproduction of NO can be harmful and result in septic shock, neurologic disorders, rheumatoid arthritis, and autoimmune diseases (Thiemermann and Vane, 1990; Evans, 1995; O'Shea et al., 2002). Therefore, inhibition of $\mathrm{NO}$ production is a very important therapeutic target in the development of anti-inflammatory agents.

The stimulation of macrophages with LPS also induces expression of the inducible isoform of nitric oxide synthase (iNOS) and cyclooxygenase-2 (COX-2) (Cao et al., 2006). High levels of NO have been described in a variety of pathophysiological processes including various forms of circulatory shock (Szabo et al., 1995), inflammation (MaPFicking et al., 1997) and carcinogenesis (Ohshima et al., 1994). iNOS is synthesized in response to several inflammatory mediators and produces $\mathrm{NO}$ in micromolar concentrations in a calcium independent manner (Wang et al., 2003). It is well known that $\mathrm{NO}$, synthesized by iNOS, releases from macrophage intimately correlated with the pathophysiology in inflammation and lots of diseases (Thiemermann $e t$ al., 1990; Kim et al., 2005) and increased expression of iNOS and its catalytic activity has been observed in several human tissues and in chemicallyinduced animal tumors and also in inflammatory disorders (Goldstein et al., 1998; Wilson et al., 1998; Ambs et al., 1998). Another enzyme that plays a important role in mediating inflammation is COX2. There are two isoform of COX, constitutively expressed COX-1 and the inducible isoform COX-2 (Kanazawa et al., 1995). COX-2 are upregulated in response to inflammatory and pro-inflammatory mediators and their products can influence many aspects of inflammatory cascade.

In the present study, we show that $\mathrm{AJ}$ significantly inhibited LPS and interferon (IFN- $\gamma$ )-induced IL-6 and NO production in a dose-dependent manner. Furthermore, the expression of iNOS and COX-2 protein were decreased.

\section{MATERIALS AND METHODS}

\section{Reagents}

LPS and sodium nitrite were purchased from Sigma (St. Louis, MO). Murine recombinant (r)IFN- $\gamma$ was purchased from Pharmingen (Mnchen, Germany). Anti-mouse IL-6, biotinylated anti- mouse IL-6 and recombinant mouse IL-6 were purchased from Pharmingen (San Diego, CA, U.S.A.).

Anti-iNOS (SantaCruz, CA, USA) and COX-2 antibody (Cayman, MI, USA) were purchased. Thioglycollate (TG) was purchased from Difco Laboratories (Detroit, MI). $0.4 \mathrm{~mm}$ syringe filter and tissue culture plates of 96 wells, 4 wells and 100-mm diameter dishes were purchased from Nunc (Naperville, IL). DMEM containing L-arginine (84 mg/l), Hank's balanced salt solution (HBSS), fetal bovine serum (FBS), and other tissue culture reagents were purchased from Life Technologies (Grand Island, NY). Male C57BL/6 mice were purchased from Damul Science Co. (Daejon, Republic of Korea).

\section{Peritoneal macrophages culture}

TG-elicited macrophages were harvested 3 - 4 days after i.p. injection of $2.5 \mathrm{ml} \mathrm{TG}$ to the mice and isolated, as reported previously (Chung et al., 2002). Using $8 \mathrm{ml}$ of HBSS containing $10 \mathrm{U} / \mathrm{ml}$ heparin, peritoneal lavage was performed. Then, the cells were distributed in DMEM, which was 
supplemented with $10 \%$ heat-inactivated FBS, in 4-well tissue culture plates $\left(2.5 \times 10^{5}\right.$ cells/well $)$ incubated for $3 \mathrm{~h}$ at $37^{\circ} \mathrm{C}$ in an atmosphere of $5 \%$ $\mathrm{CO}_{2}$, washed three times with HBSS to remove non-adherent cells, and equilibrated with DMEM that contained $10 \%$ FBS before treatment.

\section{Preparation of Albizia julibrissin (AJ)}

The dried stem bark of AJ was purchased from Korean Oriental Pharmacy Co., Ltd. in 2006. A voucher specimen (dried drug, WME003) has been deposited at the Department of Oriental Pharmacy, College of Pharmacy, Woosuk University. An extract was obtained twice from the dried sample (200 g) with 3,000 $\mathrm{ml}$ of $85 \% \mathrm{MeOH}$ under ultrasonification for $2 \mathrm{~h}$. It was evaporated and lyophilized to yield a $\mathrm{MeOH}$ extract of $\mathrm{AJ}$, which was then stored at $-20{ }^{\circ} \mathrm{C}$ until use.

\section{3-(3,4-dimethylthiazol-2-yl)-2,5-diphenyltetrazolium bromide (MTT) assay}

Cell respiration, an indicator of cell viability, was performed by the mitochondrial-dependent reduction of 3-(3,4-dimethylthiazol-2-yl)-2,5-diphenyltetrazolium bromide (MTT) to formazan, as described by Mosmann (Mosmann et al., 1983). The extent of the reduction of MTT to formazan within cells was quantified by measuring the optical density at 540 $\mathrm{nm}$ using an automated microplate reader (GENios, Tecan, Austria).

\section{IL-6 cytokine assay}

Cytokine assay was performed by a modified ELISA, as described previously (Kim et al., 2001). The ELISA was devised by coating 96- well plates with mouse monoclonal Ab specific to IL-6. Before subsequent steps in the assay, coated plates were washed with PBS containing $0.05 \%$ Tween 20 . All reagents used in this assay were incubated for $2 \mathrm{~h}$ at $37^{\circ} \mathrm{C}$. Recombinant IL-6 was diluted and used as a standard. Serial dilutions starting from $10 \mathrm{ng} /$ $\mathrm{ml}$ were used to establish the standard curve. Assay plates were exposed sequentially to biotinylated mouse IL- 6 avidin peroxidase, and ABTS substrate solution containing $30 \% \mathrm{H}_{2} \mathrm{O}_{2}$. The plates were read at $405 \mathrm{~nm}$.

\section{Measurement of nitrite concentration}

Peritoneal macrophages $\left(2.5 \times 10^{5}\right.$ cells/well $)$ were cultured with various concentrations of AJ. The cells were then stimulated with rIFN- $\gamma(20 \mathrm{U} / \mathrm{ml})$. After $6 \mathrm{~h}$, the cells were finally treated with LPS (10 $\mathrm{mg} / \mathrm{ml})$. NO synthesis in cell cultures was measured by a microplate assay method, as previously described (Chung et al., 2002). To measure nitrite, $100 \mathrm{ml}$ aliquots were removed from conditioned medium and incubated with an equal volume of Griess reagent (1\% sulfanilamide/0.1\% N-(1-naphtyl)ethylenediamine dihydrochloride/2.5\% $\left.\mathrm{H}_{3} \mathrm{PO}_{4}\right)$ at room temperature for $10 \mathrm{~min}$. The absorbance at $540 \mathrm{~nm}$ was determined by an automatic microplate reader. $\mathrm{NO}_{2}^{-}$was determined by using sodium nitrite as a standard. The cell-free medium alone contained 5 to $9 \mathrm{mM}$ of $\mathrm{NO}_{2}^{-}$. This value was determined in each experiment and subtracted from the value obtained from the medium with peritoneal macrophages.

\section{Western blot analysis}

Peritoneal macrophages $\left(5 \times 10^{6}\right.$ cells/well $)$ were pretreated with various concentrations AJ. The cells were then incubated with for $6 \mathrm{~h}$ with rIFN- $\gamma$ $(20 \mathrm{U} / \mathrm{ml})$. They were finally stimulated with LPS $(10 \mathrm{mg} / \mathrm{ml})$ for $24 \mathrm{~h}$. Whole cell lysates were made by boiling peritoneal macrophages in sample buffer (62.5 mM Tris-HCl, $\mathrm{pH}$ 6.8, 2\% sodium dodecyl sulfate (SDS), 20\% glycerol, and 10\% 2mercaptoethanol). Proteins in the cell lysates were then separated by 10\% SDS-polyacrylamide gel electrophoresis and transferred to nitrocellulose paper. The membrane was then blocked with 5\% skim milk in PBS-tween-20 (Sigma) for $1 \mathrm{~h}$ at room temperature and then incubated with anti-iNOS or COX-2 antibody. After washing in with phosphatebuffered saline (PBS) containing 0.05\% tween-20 three times, the blot was incubated with secondary 
antibody for $1 \mathrm{~h}$ and the antibody-specific proteins were visualized by the enhanced chemiluminesence detection system according to the recommended procedure (Amersham Corp. Newark, NJ).

\section{Statistical analysis}

Results were expressed as the mean \pm S.E.M. of independent experiments, and statistical analysis was performed by one-way analysis of variance (ANOVA) to express the difference among the groups.

\section{RESULTS}

\section{Effects of AJ on cell viability}

To determine the effects of $\mathrm{AJ}$ on viability of mouse peritoneal macrophages, we carried out MTT assay. Cell cytotoxicity by AJ was not observed (Fig. 1).

\section{Effect of AJ on IL-6 production}

The effect of AJ was tested on IL-6 production from LPS-treated mouse peritoneal macrophages. As shown in Fig. 2, IL-6 production in response to LPS was inhibited by pre-treatment with 1, 10 and $100 \mu \mathrm{g} / \mathrm{ml} \mathrm{AJ}$ in a dose-dependent manner, IL-6 production by AJ $(100 \mu \mathrm{g} / \mathrm{ml})$ was significantly inhibited.

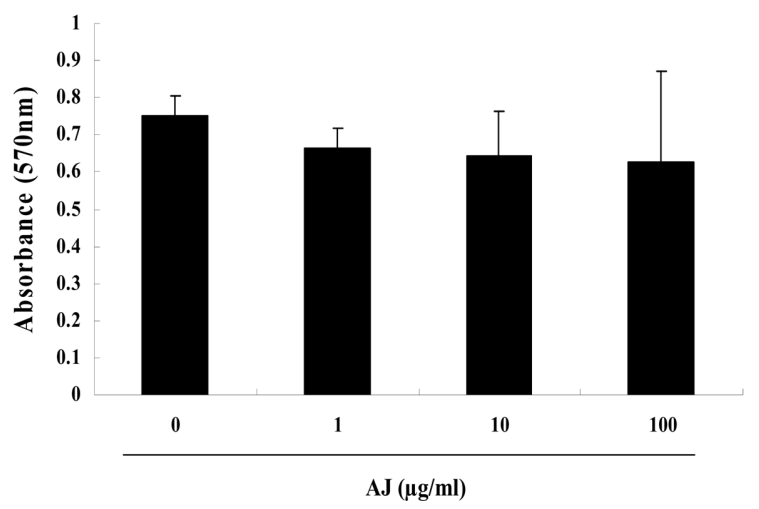

Fig. 1. Effect of AJ on the cell viability. Cell viability was evaluated by MTT colorimetric assay $48 \mathrm{~h}$ after AJ treatment in peritoneal macrophages. Values are the mean \pm S.E.M. of three independent experiments duplicate in each run.

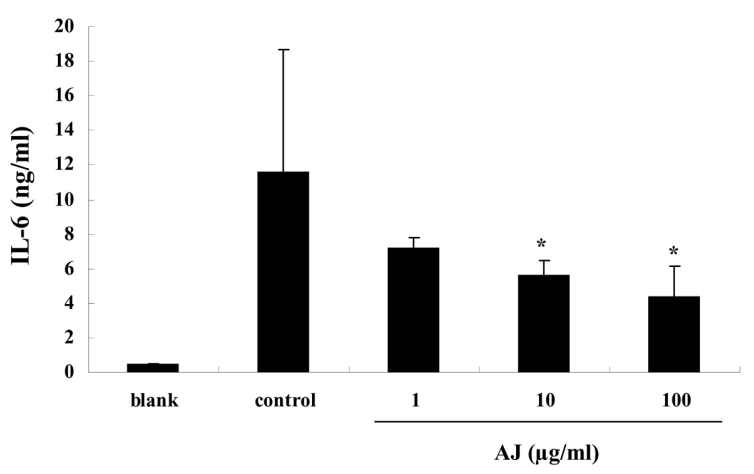

Fig. 2. Effect of AJ on Cytokine Production. Cells $(3 \times$ $10^{5}$ cells $\left./ \mathrm{ml}\right)$ were pretreated with $\mathrm{AJ}(0.01-1 \mathrm{mg} / \mathrm{ml})$ for $30 \mathrm{~min}$, and then stimulated with IFN-g + LPS (10 $\mathrm{mg} / \mathrm{ml}$ ) for $24 \mathrm{~h}$. Cytokine levels in supernatant were measured using ELISA. All data represent the mean \pm S.E.M. of three independent experiments. $P<0.05$, significantly different from the IFN- $\gamma+$ LPS-stimulated cells.

\section{Effects of $\mathrm{AJ}$ on $\mathrm{NO}$ production}

To determine the effect of $\mathrm{AJ}$ on the production of NO by mouse peritoneal macrophages, we pretreated the cells with various concentration $\mathrm{AJ}(1,10,100 \mu \mathrm{g} /$ $\mathrm{ml})$ and stimulated them with rIFN- $\gamma(20 \mathrm{U} / \mathrm{ml})$ and LPS $(10 \mathrm{mg} / \mathrm{ml})$. The resultant NO production was determined by detecting nitrite concentrations in the cell supernatants after $48 \mathrm{~h}$ treatment. When mouse peritoneal macrophages were primed for $6 \mathrm{~h}$ with murine rIFN- $\gamma$ and then treated with LPS, $\mathrm{NO}$ production was increased about 10 folds. AJ had no effect on NO production in resting mouse peritoneal macrophages compared to non-primed conditions. When AJ was pretreated in primed cell, AJ inhibits NO production dose dependently (Fig. 3).

Effects of AJ on expression of iNOS and COX-2 protein

In order to investigate the mechanism of action of AJ on the inhibition of $\mathrm{NO}$ production, this experiment was performed. We investigate the effect of the AJ at translational level by western blotting. As shown in Fig. 4, the expression of iNOS was increased after rIFN- $\delta(20 \mathrm{U} / \mathrm{ml})$ plus LPS $(10 \mu \mathrm{g} / \mathrm{ml})$ challenge for $24 \mathrm{~h}$. This enhanced expression of iNOS was significantly reduced by AJ $(100 \mu \mathrm{g} / \mathrm{ml})$. We 


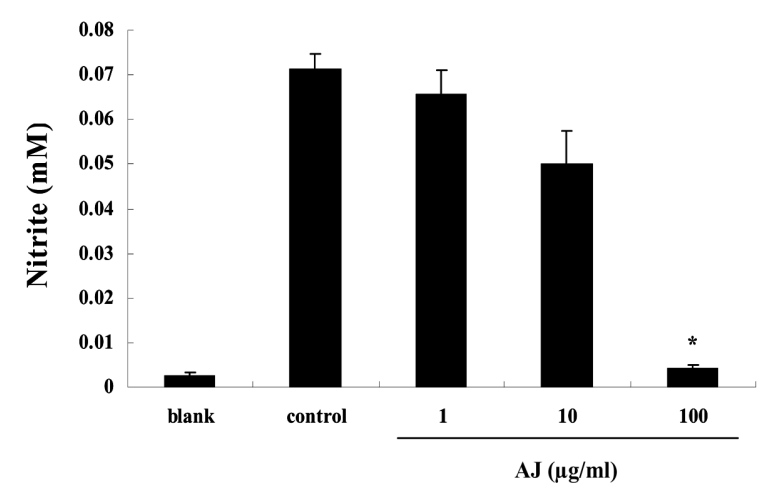

Fig. 3. Dose-dependent effects of AJ on NO inhibition in rIFN- $\gamma$ and LPS-treated peritoneal macrophages. Peritoenal macrophages $\left(2.5 \times 10^{5}\right.$ cells/well $)$ were cultured with various concentration AJ. The peritoneal macrophages were then stimulated with rIFN- $\gamma(20$ $\mathrm{U} / \mathrm{ml}$ ) and LPS $(10 \mathrm{mg} / \mathrm{ml})$. After $48 \mathrm{~h}$ of culture, NO release was measured by the Griess method (nitrite). NO (nitrite) released into the medium is presented as the mean \pm S.E.M. of three independent experiments duplicate in each run. ${ }^{*} P<0.001$ compared to rIFN- $\gamma+$ LPS.

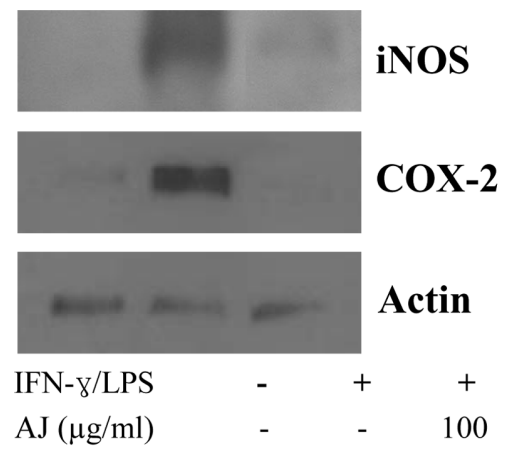

Fig. 4. Effects of AJ on the expression of iNOS and COX-2 by rIFN- $\gamma$ plus LPS-induced peritoneal macrophages. Peritoneal macrophages $\left(5 \times 10^{6}\right.$ cells/well $)$ were pretreated with $\mathrm{AJ}$ and then stimulated for $6 \mathrm{~h}$ with rIFN- $\gamma(20 \mathrm{U} / \mathrm{ml})$. The peritoneal macrophages were then stimulated with LPS $(10 \mathrm{mg} / \mathrm{ml})$ for $24 \mathrm{~h}$. The protein extracts were prepared, and then samples were analyzed for iNOS and COX-2 expression by Western blotting as described in the method. 1, blank; 2, rIFN- $\gamma$ + LPS; 3, AJ (100 mg/ml) + rIFN- $\gamma$ + LPS.

investigated the effect of the $\mathrm{AJ}$ at translational level. The expression of COX-2 protein was markedly increased after IFN- $\gamma(20 \mathrm{U} / \mathrm{ml})$ plus LPS $(10 \mathrm{mg} /$ $\mathrm{ml}$ ) challenge for $24 \mathrm{~h}$. This increased expression of COX-2 protein was significantly reduced by AJ (Fig. 4).

\section{DISCUSSION}

We show that AJ significantly inhibited LPS and IFN- $\gamma$-induced IL-6 and NO production in a dosedependent manner. Furthermore, the expression of iNOS and COX-2 protein was decreased.

Pro-inflammatory cytokine such as IL-6 mediates the development of various inflammatory reactions (Dinarello, 2000). In this study, we showed that AJ effectively inhibited the production and mRNA expression of IL-6 cytokine on LPS-stimulated peritoneal macrophages. These results suggest that AJ might have an anti-inflammatory activity.

Murine macrophage exhibits a particularly vigorous response to endotoxin, which induces production of variety of inflammatory modulators such as NO, PGE 2 by iNOS and COX-2 respectively. $\mathrm{NO}$ has been recognized to be an important mediator of cellular communication in several preparations such as macrophages, neutrophils, smooth muscle, autonomic nervous system, and central nervous system (Koyanagi et al., 2000; Blackman et al., 2000; Sharma et al., 2000). At this point of view, we evaluated the effect of methanol extract of $\mathrm{AJ}$ on $\mathrm{NO}$ production in IFN- $\gamma$ and LPS stimulated mouse peritoneal macrophages. In this study, exposure of macrophages to IFN- $\gamma$ and LPS for $48 \mathrm{~h}$ was associated with an accumulation of nitrite in the medium, suggesting an enhanced NO production. This IFN- $\gamma$ and LPS-induced NO production was inhibited dosedependently by AJ without notable cytotoxicity (Fig. 1 and 3).

$\mathrm{NO}$ produced by one of three kinds of $\mathrm{NO}$ synthases (NOS) that neuronal NOS (nNOS), endothelial NOS (eNOS), inducible NOS (iNOS). nNOS and eNOS were critical to normal physiology and thus, inhibition of these enzymes caused damage. In the contrary, the level of iNOS playing a crucial role of excess production of $\mathrm{NO}$ in activated macrophages. Therefore, suppression of NO production via inhibition of iNOS expression levels might be an attractive therapeutic target for 
the treatment of numerous pathological conditions, including inflammation. Thus the possibility that AJ might inhibit iNOS expression was examined and AJ suppressed the expression of iNOS significantly in IFN-g and LPS-stimulated mouse peritoneal macrophages (Fig. 4).

COX, another key enzyme in inflammation, is the rate-limiting enzyme that catalyzes the formation of prostaglandins (PGs) from arachidonic acid. Levels of PGs increase early in the course of the inflammation (Wallace et al., 1999). Like NOS, COX also exists in both constitutive (COX-1) and inducible (COX-2) forms. It is well known that the COX-1 is a housekeeping protein in most tissues and it catalyzes the synthesis of PGs for normal physiological functions. In constant, inducible isoform, COX-2, is rapidly stimulated by tumor promoters, growth factors, cytokines and pro-inflammatory molecules (Minghetti et al., 1998) and responsible for the production of the high levels of PGs in several pathological conditions such as inflammation. Since, COX-2 is induced by stimulation in inflammatory cells, inhibitors of COX-2 induction might candidates for the new type of nonsteroidal anti-inflammatory drugs. We documented the increased production of COX-2 protein by macrophages exposed to IFN- $\gamma$ and LPS. IFN- $\gamma$ and LPS in combination with PF led to a significant reduction in COX-2 protein expression (Fig. 4). Thus, it seems quite reasonable to speculate that $\mathrm{AJ}$ may inhibits $\mathrm{PGE}_{2}$ production. However, further studies are required to determine whether $\mathrm{AJ}$ is selective inhibitor of COX-2.

Here in our study, we have shown that AJ exerts its anti-inflammatory effects probably by the suppression of iNOS and COX-2 expression, and the final result is the inhibition of $\mathrm{NO}$ synthesis. Based on our present results, it is possible that $\mathrm{AJ}$ can offer a valuable means of therapy for the treatment of inflammatory diseases by attenuating IFN- $\gamma$ and LPS-induced NO synthesis and controlling of iNOS and COX-2 expression.

\section{ACKNOWLEDGEMENTS}

This work was supported by the Research Grant from Woosuk University.

\section{REFERENCES}

The Pharmacopoeia Committee of People's Republic of China (ed.), (1995) "Pharmacopoeia (I)," People Health Press, Beijing, 119-120.

Adams DO, Hamilton TA. (1984) The cell biology of macrophage activation. Annu. Rev. Immunol. 2, 283318.

Ambs S, Merriam WG, Bennett WP, Felley-Bosco E, Ogunfusika MO, Oser SM, Klein S, Shields PG, Billiar TR, Harris CC. (1998) Frequent nitric oxide synthase-2 expression in human colon adenomas: implication for tumor angiogenesis and colon cancer progression. Cancer Res. 58, 334-341.

Beutler B. (1995) TNF, immunity and inflammatory disease: lessons of the past decade. J. Invest. Med., 43, 227-235.

Beutler B. (2000) Tlr4: central component of the sole mammalian LPS sensor, Curr. Opin. Immuno. 12, 2026.

Blackman DJ, Morris-Thurgood JA, Atherton JJ, Ellis G.R, Anderson RA, Cockcroft JR, Frenneaux MP. (2000) Endothelium-derived nitric oxide contributes to the regulation of venous tone in humans. Circulation 18, 165-170.

Chung HS, Jeong HJ, Hong SH, Kim MS, Kim SJ, Song BK, Jeong IS, Lee EJ, Ahn JW, Baek SH. Kim HM. (2002) Induction of nitric oxide synthase by Oldenlandia diffusa in mouse peritoneal macrophages. Biol. Pharm. Bull. 25, 1142-1146.

Dinarello CA. (2000) Proinflammatory cytokines. Chest 118, 503-508.

Goldstein SR, Yang GY, Chen X, Curtis SK, Yang CS. (1998) Studies of iron deposits, inducible nitric oxide synthase and nitrotyrosine in a rat model for esophageal adenocarcinoma. Carcinogenesis 19, 1445-1449.

Kanazawa K., Kawasaki H, Samejima K, Ashida H, Danno G.. (1995) Specific desmutagen (antimutagen) in oregano against a dietary carcinogen, Trp-P-2, are galangin and quercetin. J. Agric. Food Chem. 43, 404-409. 
Kim MS, Lim WK, Cha JG, An NH, Yoo SJ, Park JH, Kim HM, Lee YM. (2001) The activation of PI 3-K and PKC zeta in PMA-induced differentiation of HL-60 cells. Cancer Lett. 171, 79-85.

Koyanagi M, Egashira K, Kubo-Inoue M, Usui M, Kitamoto S, Tomita H, Shimokawa H, Takeshita A. (2000) Role of transforming growth factor-beta1 in cardiovascular inflammatory changes induced by chronic inhibition of nitric oxide synthesis. Hypertension 35, 86-90.

Medzhitov R, Janeway CA Jr. (1997a) Innate immunity: the virtues of a nonclonal system of recognition. Cell 9, 295-298.

Medzhitov R, Janeway CA. (1997b) Innate immunity: impact on the adaptive immune response., Curr. Opin. Immunol. 9, 4-9.

Minghetti L, Levi G. (1998) Microglia as effector cells in brain damage and repair: focus on prostanoids and nitric oxide. Prog. Neurobiol. 54, 99-125.

Mosmann T. (1983) Rapid colorimetric assay for cellular growth and survival: application to proliferation and cytotoxicity assays. J. Immunol. Methods 65, 55-63.

Parrillo JE. (1993) Pathogenetic mechanisms of septic shock. New Engl. J. Med. 328, 1471-1477.

Remick DG, Strieter R.M, Eskandari MK, Nguyen DT, Genord MA, Raiford CL, Kunkel SL. (1990) Role of tumor necrosis factor-alpha in lipopolysaccharide- induced pathologic alterations. Am. J. Pathol. 136, 49-60.

Sharma R, Coats AJ, Anker SD. (2000) The role of inflammatory mediators in chronic heart failure: cytokines, nitric oxide, and endothelin-1. Int. J. Cardiol. 15, 175-186.

Thiemermann C, Vane J. (1990) Inhibition of nitric oxide synthesis reduces the hypotension induced by bacterial lipopolysaccharides in the rat in vivo. Eur. J. Pharmacol. 182, 591-595.

Vilcek J, Lee TH. (1991) Tumor necrosis factor. New insights into the molecular mechanisms of its multiple actions. J. Biol. Chem. 266, 7313-7316.

Wallace JL. (1999) Distribution and expression of cyclooxygenase (COX) isoenzymes, their physiological roles, and the categorization of nonsteroidal antiinflammatory drugs (NSAIDs). Am. J. Med., 13, 107, 11S-16S; discussion 16S-17S.

Wilson KT, Fu S, Ramanujam KS, Meltzer SJ. (1998) Increased expression of inducible nitric oxide synthase and cyclooxygenase-2 in Barrett's esophagus and associated adenocarcinomas. Cancer Res., 58, 29292934.

Zhang RY. (1999) Pharmacopoeia Committee of China. Chinese Pharmacopoeia, C-hemical Industry Press: Beijing, 2005; Vol. 1, p 97. S. Q.; Chem. J. Chin. Univ. 20, 1877. 